\title{
Thorax: the teenage years
}

\section{Andrew Bush, ${ }^{1}$ lan Pavord ${ }^{2}$}

We have been at the helm for 18 monthswhere have we got to, where should we aim for (other than staying out of the divorce courts)?

\section{WHAT A TEAM! \\ Napoleon preferred lucky generals, and Thorax has lucky Editors in Chief because we have a great team of deputy editors, associate editors, production staff and editorial board. A former Editor in Chief (it is said!) used to write to authors to say either "I am sorry, but the Associate Editor has recommended rejection of your manuscript" or "I am pleased to tell you I that have accepted your paper". By contrast, we feel our brilliant team take the credit for what has gone right-any mistakes are rightly laid at the door of the undersigned. They have all worked exceedingly hard, and our twice yearly meetings have been full of energy and enthusiasm and great fun. A big thank you to you all.}

\section{HOW WE HANDLE MANUSCRIPTS}

No process is perfect. Incoming manuscripts are checked by the staff and, if they conform to the journal style, are assigned to the Editors in Chief. Note please: we are toughening up, and if your manuscript is too long or has too many references, it will be returned unrefereed for you to edit; terseness not Tolstoy, please! Manuscripts that are reviewed positively are discussed by the Gang of Four at the weekly Hanging Committee. After Hanging Committee discussion, the decision may be to reject or, if there are any numerical data at all in the manuscript, a statistical review is obtained and a final decision taken when this review has been received. We have the statistical reviews in series not parallel because of cost and scarcity of precious statistical time. If your manuscript is rejected, of course you may

\footnotetext{
${ }^{1}$ Department of Paediatric Respiratory Medicine, Imperial College and Royal Brompton Hospital, London, UK; ${ }^{2}$ Department of Respiratory Medicine, Thoracic Surgery and Allergy, University Hospitals of Leicester NHS Trust, Glenfield Hospital, Groby Road, Leicester LE3 90P, UK

Correspondence to Professor Andrew Bush, Department of Paediatric Respiratory Medicine, Royal Brompton Hospital, Sydney Street, London SW3 6NP, UK; a.bush@imperial.ac.uk
}

appeal, and the appeal will be handled by whichever one of us did not handle the original manuscript unless there is a conflict of interest. But please, only appeal if you feel there are significant errors of fact made during the initial process, and point them out to us. Editorial priority (aka whims) is inevitably arbitrary and does change as new manuscripts are accepted. All authors (including ourselves) allocate the highest priority to their own work, and feel editors who disagree were not merely conceived out of wedlock but have an IO beginning with a minus sign. This assessment may be true, but expressing it will not get a decision overturned.

\section{ANOTHER GREAT TEAM!}

We rely heavily on our reviewers, and we are grateful to so many for thoughtful and timely opinions on the excellent manuscripts we receive. Please keep them coming. A new initiative will get referees CME points-reviews will be scored 1-3 on timeliness and content, and accumulating 6 points gives the reviewer one CME credit. A small token of our appreciation, but better than a poke in the eye with a wet stick or the chance to take part in yet another round of NHS reforms.

\section{JOURNAL STATISTICS}

We are getting between 100 and 180 manuscripts a month; many tough priority decisions have to be made and the acceptance rate is just over $10 \%$-sorry! The editorial process has been speeding up. Typically, we reach a decision on all manuscripts within 40 days and, in the last 6 months, the average time for a decision for reviewed manuscripts has been less than 30 days. All this is good, but we are doing less well around August. Unsurprisingly, we are all human and all need a break. We will work on ways to address this but, remember, if you hit the submit button just before heading out to the Costa del Relaxation, the AEs and reviewers may also be hitting the 'gone fishing' button at the same time.

\section{IMPACT FACTOR}

What is not good is the fall in the impact factor to 6.525. We are still ahead of our two main rivals, Chest and the European
Respiratory Journal, and we are working hard to reverse the trend. We feel more could be done (see below).

\section{A REMINDER-RANDOMISED CONTROLLED TRIALS}

We have recently published some excellent clinical trials ${ }^{1-6}$ and we want more. Investigators-remember our previous offer. ${ }^{7}$ Send us your final protocol and we will peer review it. If we accept it and you send us the final manuscript (we don't expect exclusivity), we will fast track it-the only reviewing issue will be whether you have done what you said you would; and if you have, positive or negative results, we will publish your manuscript. However, do not expect acceptance if you recruited only 8 of 250 patients!

\section{AN ADOLESCENT TANTRUM}

We have been helped enormously by the publishers, and special mentions for tolerance and efficiency go to Claire Weinberg (surely working with us cannot be worse than childbirth, Claire?), Allison Lang, Bryony Lovelock and Sarah Szatkowski who have steered the ship through the rocky places of ScholarOne. We are profoundly grateful to them all. We have more content than ever free online, including Airwaves, Editors' choice and a Hot Topic, and times to online publication have dropped dramatically; all this is great. On the other hand, online access to old manuscripts is locked from 2006, an unfortunate contrast to our two main rivals, American Journal of Respiratory and Critical Care Medicine and Chest, who have open access to all manuscripts after a year. We are working hard to correct this inequity and would value our readers' support.

\section{A POSITIVE ENDING: NEW INITIATIVES}

The new Chest Clinic session is up and running and will be formally evaluated shortly. We are keen to receive more casebased discussions. Please do not send obscure case reports; we want genuine grey cases with clinically important educational points. Finally, we have had two themed issues this year: Lung cancer (April) and Smoking (October). We were particularly pleased with the publicity arising from the issue on Smoking which reached the dizzying academic heights of 'Loose Women', among others. We plan another ATS themed issue for April for distribution in San Francisco. We would welcome suggestions for further themed issues, assuming this is a popular ideaplease let us know! 


\section{Competing interests None.}

Provenance and peer review Commissioned internally peer reviewed.

Thorax 2012;67:1-2

doi:10.1136/thoraxinl-2011-201340

\section{REFERENCES}

1. Crichton F, Ramsay CF, Pearson D, et al. Oral montelukast in acute asthma exacerbations: a randomised, double-blind, placebo-controlled trial. Thorax 2011;66:7-11
2. Moore RP, Berlowitz DJ, Denehy L, et al. A randomised trial of domiciliary, ambulatory oxygen in patients with COPD and dyspnoea but without resting hypoxaemia. Thorax 2011;66:32-7.

3. Churchyard GJ, Fielding K, Surita Roux S, et al. Twelve-monthly versus six-monthly radiological screening for active case-finding of tuberculosis: a randomised controlled trial. Thorax 2011;66:134-9.

4. Fischer BM, Mortensen J, Hansen $\mathrm{H}$, et al. Multimodality approach to mediastinal staging in nonsmall cell lung cancer. Faults and benefits of PET-CT: a randomised trial. Thorax 2011;66:294-300.
5. Perrin K, Wijesinghe M, Healy B, et al. Randomised controlled trial of high concentration versus titrated oxygen therapy in severe exacerbations of asthma Thorax 2011;66:937-41.

6. Christophe $\mathbf{M}$, Pison CM, Cano NJ, et al; The IRAD Investigators. Multimodal nutritional rehabilitation improves clinical outcomes of malnourished patients with chronic respiratory failure: a randomised controlled trial. Thorax 2011;66:953-60

7. Bush A, Pavord I. New Year resolutions. Thorax 2011;66:91-2

\section{Is air pollution of the 20th century a cause of current asthma hospitalisations?}

\section{Nino Künzli ${ }^{1,2}$}

Danish researchers followed $>57000$ older people over 10 years up to 2006. ${ }^{1}$ They made unique efforts to individually estimate exposure to traffic-related pollution for 35 years back in time, using modelled home-outdoor nitrogen dioxide $\left(\mathrm{NO}_{2}\right)$ concentrations. A $5.8 \mu \mathrm{g} / \mathrm{m}^{3}$ contrast in the 35-year average $\mathrm{NO}_{2}$ concentration was associated with a $10 \%$ higher risk for a first-ever hospitalisation due to asthma. In other words, pollution of the last century appears to contribute to current hospitalisations. But does this interpretation make sense? First, I will present arguments against this conclusion. Second, I will explain how to make sense of this large and well-conducted study.

To clarify the interpretation of the results, it is worth formulating two basic hypotheses relevant to research on air pollution and chronic diseases like asthma where underlying chronic pathologies (eg, hyper-reactive airways) are superimposed by acute expressions of the chronic disease (eg, asthma attacks). ${ }^{2}$ Under this model, two primary hypotheses emerge for exposure to air pollution:

- H1: Exposure supports the development of the underlying chronic pathology and, thus, increases the pool of people with chronic conditions (chronic effects) prone to exacerbations or 'events'

${ }^{1}$ Swiss Tropical and Public Health Institute, Basel, Switzerland; ${ }^{2}$ University of Basel, Basel, Switzerland

Correspondence to Dr Nino Künzli, Department of Epidemiology and Public Health, Swiss Tropical and Public Health Institute, Socinstrasse 57, PO Box, 4002 Basel, Switzerland; nino.kuenzli@unibas.ch
- H2: Exposure triggers an acute event (or a state of frailty that results in an event with a delay of a few days or weeks) among those with the disease (acute and subacute effects).

In $\mathrm{H} 2$, the underlying cause of the asthma cases may (H1) or may not be air pollution. While mechanisms related to the two hypotheses are not necessarily independent, there are possibly different causes and pathways involved in the two time domains of effects. For example, exposure to cold air may trigger an asthma attack, while living in a colder climate may not necessarily relate to higher incidence of asthma.

$\mathrm{H} 2$ has been well studied for a range of events (including hospital admissions) shown to be associated with the level of pollution in previous hours, days or few weeks. ${ }^{3} \mathrm{H} 1$ assumes instead that a chronic disease process is supported by long-term exposures to air pollution; therefore, classic $\mathrm{H} 2$ studies (eg, time series analyses and panel studies) with exposure terms derived for a few days or weeks do not address H1. The Danish study uses an estimate of (very) long-term exposure and, thus, the question arises whether it provides evidence for adult-onset asthma incidence $(\mathrm{H} 1) .{ }^{1}$ Investigating the chronic consequences of pollution requires indeed an estimate of long-term exposure; however, this is, by itself, not sufficient. $\mathrm{H} 1$ research also requires an appropriate 'chronic' health outcome. If H2 is true, I would argue that event-based outcomes (eg, asthma attacks, hospitalisation, death) are not the right choice to investigate $\mathrm{H} 1-$ no matter what data one may have at hand.
Related concepts have been discussed in interpreting mortality studies ${ }^{4}$ or chronic cardiovascular pathologies. ${ }^{2}$ Let me apply these issues to asthma.

Let us pretend that $\mathrm{H} 1$ cannot be possible; thus, all we need to investigate are the acute or subacute effects $(\mathrm{H} 2)$. While $\mathrm{H} 2$ can be well explored in classic 'acute effect studies', correlating yesterday's pollution with today's event frequencies, $\mathrm{H} 2$ could also be studied in cross-sectional surveys or in cohort studies even if the only available exposure term was some longterm mean concentration, such as in the study by Andersen et al. ${ }^{1}$ Under $\mathrm{H} 2$, 'period prevalence' of exacerbations or the frequency of hospitalisations must also be associated with the average 'long-term' concentration of pollution. This is not because the triggering of events would require cumulating exposures over months or years, but because a cleaner site has, on average, better air quality than a polluted site, both in the long term and in the short term. Accordingly, in clean sites air pollution related events are less frequent than in polluted places. To identify the relevant time windows of exposure one would need independent estimates of the various periods of exposure. The Danish study could-in theory-indeed investigate the independent effects of pollution during the week, month, season or year(s) prior to the hospital admission. In practice, this was not possible as the short-term exposure windows (days) prior to hospital admission were not available while the 1-, 15- and 35year estimates of 'long-term exposure' were so highly correlated that 'multiperiod' models could not be run. Conclusions made for the 35-year exposure also apply to the 15 years and the last 1-year mean (for which they observed the largest coefficients). As outlined above, the annual mean prior to the hospitalisation is expected to correlate with hospitalisations under $\mathrm{H} 2$ alone. In conclusion, the study confirms that air pollution affects asthma related hospital admissions but provides no 